\title{
AXAIR and PUFF-PLUME Comparison (U)
}

by

A. A. Simpkins

Westinghouse Savannah River Company

Savannah River Site

Aiken, South Carolina 29808

R. J. Kurzeja

DOE Contract No. DE-AC09-89SR18035

This paper was prepared in connection with work done under the above contract number with the U.S.

Department of Energy. By acceptance of this paper, the publisher and/or recipient acknowledges the U.S. Government's right to retain a nonexclusive, royalty-free license in and to any copyright covering this paper, along with the right to reproduce and to authorize others to reproduce all or part of the copyrighted paper. 
Waste Management and Environmental Technology

\title{
AXAIR AND PUFF-PLUME COMPARISON
}

\author{
A. A. Simpkins \\ R. J. Kurzeja
}

November 1993

Westinghouse Savannah River Company

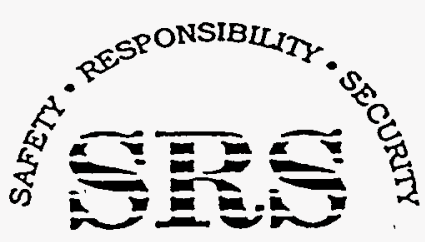




\section{DISCLAIMER}

This report was prepared as an account of work sponsored by an agency of the United States Government. Neither the United States Government nor any agency thereof, nor any of their employees, make any warranty, express or implied, or assumes any legal liability or responsibility for the accuracy, completeness, or usefulness of any information, apparatus, product, or process disclosed, or represents that its use would not infringe privately owned rights. Reference herein to any specific commercial product, process, or service by trade name, trademark, manufacturer, or otherwise does not necessarily constitute or imply its endorsement, recommendation, or favoring by the United States Government or any agency thereof. The views and opinions of authors expressed herein do not necessarily state or reflect those of the United States Government or any agency thereof. 


\section{DISCLAIMER}

Portions of this document may be illegible in electronic image products. Images are produced from the best available original document. 
WSRC-RP-93-1322

\author{
Key Words Dispersion \\ Dose Determination \\ Atmospheric Release \\ Source Term
}

Retention: Lifetime

\title{
AXAIR AND PUFF-PLUME COMPARISON
}

A. A. Simpkins

R. J. Kurzeja

Issued: November 1993

SRTC

SAVANNAH RIVER TECHNOLOGY CENTER

AIKEN, SC 29808

Westinghouse Savannah River Company Savannah River Site

Aiken, SC 29808

PREPARED FOR THE U.S. DEPARTMENT OF ENERGY UNDER CONTRACT NO. DE-AC09-88SR18035 
A test version of AXAIR has been prepared to compare with PUFF-PLUME. The test version of AXAIR applies the same meteorological conditions as PUFFPLUME and also the dispersion coefficients have been changed to be the same as those in PUFF-PLUME. The test version of AXAIR and PUFF-PLUME produce virtually the same doses with the differences being less than $3 \%$ for the select cases with similar input. Differences and similarities in the models are also addressed. 


\section{TABLE OF CONTENTS}

1.0 INTRODUCTION ……..................................................................................

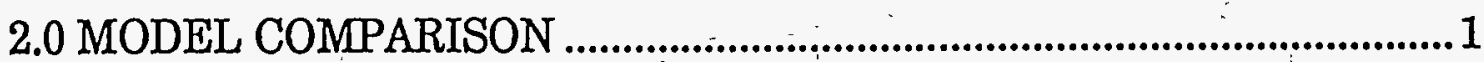

3.0 EXPECTED MODEL DIFFERENCES ................................................. 4

3.1 Release Height Correction ...................................................................... 4

3.2 Fumigation ............................................................................................

3.3 Interpolation .......................................................................................

3.4 Source Size .........................................................................................

3.5 Inversion Height ..............................................................................

3.6 Inhalation and Shine Doses ............................................................

3.7 Meander ..........................................................................................

3.8 Breathing Rates ...................................................................................

4.0 CONCLUSTONS .................................................................................... 8

5.0 REFERENCES ……............................................................................

APPENDIX A

APPENDIX B 


\section{LIST OF TABLES}

Table 1. Dose Comparison of AXAIR vs PUFF-PLUME 3

Table 2. Dose Comparison of AXAIR vs PUFF-PLUME 3

Table 3. Dose Comparison of AXAIR vs PUFF-PLUME ................................ 3

Table 4. Wind Speed Category Ranges ...........................................................6

Table 5. Sample Ranking of Dose ................................................................. 


\title{
AXAIR AND PUFF-PLUME COMPARISON
}

\author{
By A. A. Simpkins and R. J. Kurzeja \\ Westinghouse Savannah River Company \\ Savannah River Site \\ Aiken, SC 29808
}

\subsection{INTRODUCTION}

AXAIR and PUFF-PLUME are Gaussian models used by SRTC's Environmental Technology Section (ETS) to estimate concentrations and doses from atmospheric releases. But whereas AXAIR is primarily used to produce documentation for safety related purposes, PUFF-PLUME is used for emergency response (real-time). Thus AXAIR applications invariably involve a range of meteorological conditions(database), whereas PUFF-PLUME is applied to a single event.

AXAIR and PUFF-PLUME each evolved over 10-15 years and have usually been used independently. Recently however, the two models have been applied to the same problems and sometimes have produced different results during operational use. For this reason a decision was made to compare the models for cases where the models should agree. An additional task was to discuss situations where they are not expected to agree due to inherent differences in the models.

Currently the primary differences in the models are: meteorological data, dispersion coefficients, and display and format of input and output. AXAIR accesses a site-specific, five-year meteorological data base containing a joint frequency distribution categorized by seven stability classes and six wind speed categories for each of the sixteen sectors centered on the release location. PUFFPLUME uses real-time meteorology or user-input of stability, wind speed and direction. PUFF-PLUME uses Pasquill's ${ }^{1}$ lateral dispersion model and Briggs ${ }^{2}$ vertical dispersion coefficients. On the other hand, AXAIR uses equations estimated by the graphical representation of the diffusion coefficients estimated by Pasquill $3,4,5$.

\subsection{MODEL COMPARISON}

The first objective of the study was to compare the two models under similar conditions. The cases used for the comparison were carefully chosen so that differences in input between the two models could be minimized. Internal modifications to the FORTRAN were also necessary to conduct a true comparison. 
of the horizontal $\left(\sigma_{\theta}\right.$ or $\sigma_{\mathrm{a}}$ ) and vertical $\left(\sigma_{\mathrm{e}}\right)$ wind direction and the wind speed being input by the user. In contrast to PUFF-PLUME, AXAIR does not have the option of entering a single specific stability and wind data. Instead, calculations are automatically made for a range of stability and wind classes and the user selects an exceedance probability (either $99.5 \%$ or $50 \%$ ). Thus, in general a rigorous comparison is not possible to the casual user.

AXAIR determines the $99.5 \%$ dose value by ranking all of the calculated doses by sector from highest to lowest along with their respective cumulative frequency, stability class and wind speed class. In each sector, whenever the desired fraction has been exceeded ( 0.5 for the $99.5 \%$ ) the model interpolates between this value and the previous value. Modifications can be made to the meteorological database to have the model select a specific direction, stability class, and wind speed to determine the $99.5 \%$ dose.

To compare with PUFF-PLUME, the joint frequency distribution is modified so that the frequency is set to zero everywhere except for the category with the desired wind speed and stability, which is set to 0.5. This is the category the model will then choose as the $99.5 \%$ for the selected sector. AXAIR prints the frequencies as a function of wind speed and direction as part of the output so the correct category was easily verified. Data concerning the wind speeds corresponding to the specific category were also changed to agree with the input wind speed to PUFF-PLUME.

Another minor adjustment made in the AXAIR input was to select a stack release height equal to that input into PUFF-PLUME. In AXAIR an adjustment is automatically made to the stack release height to account for the terrain per NRC Reg. Guide $1.145^{5}$. The effective stack height is the release height minus the maximum terrain height between the release point and the receptor. For the particular case used for the comparison later, the difference was $2.74 \mathrm{~m}$. In order to get a true comparison, one case was run with the stack release height in AXAIR increased $3 \mathrm{~m}$ (AXAIR will only accept whole numbers for release height) so that the effective stack height would be the same as the value used in the PUFF-PLUME case. The effective stack height difference is addressed further in section 3.1.

The current operational version of AXAIR uses different dispersion coefficients than PUFF-PLUME. A test version of AXAIR was created with the dispersion coefficients changed to Pasquill for $\sigma_{\mathrm{y}}$ and Briggs for $\sigma_{\mathrm{z}}$. The equations for each of these can be seen in references 6 and 7. A new verified version of AXAIR is expected to be released in the spring and it will contain these dispersion coefficients. PUFF-PLUME assumes 6 stability classes (A-F) and AXAIR assumes 7 (A-G). The changes in AXAIR use the same equations for the dispersion coefficients for stability classes $F$ and $G$. This is not expected to add any error since both are stable categories.

Tables 1, 2, and 3 show the comparisons that were made between doses determined by AXAIR and PUFF-PLUME for the following stability classes and wind speeds: A $-6 \mathrm{~m} / \mathrm{s}, \mathrm{C}-4 \mathrm{~m} / \mathrm{s}, \mathrm{E}-8 \mathrm{~m} / \mathrm{s}$. These combinations were arbitrarily 
chosen from stability and wind speed combinations for which the fumigation algorithm is not invoked. All doses shown are fifty year committed effective dose equivalents. For a complete listing of the input for both models see Appendix A.

Although the models are in fairly close agreement the differences can still be attributed to inherent differences within each of the models. If a closer agreement was desired AXAIR would have to be further modified.

A comparison using the current working version of each of the codes is shown in Appendix B.

Table 1. Dose Comparison of AXAIR vs PUFF-PLUME (Stability Class A, Wind speed $6 \mathrm{~m} / \mathrm{s}$ )

\begin{tabular}{|c|c|c|c|}
\hline \multirow{2}{*}{ Distance $(\mathrm{km})$} & \multicolumn{2}{|c|}{ Dose (mrem) } & Percent Diff. \\
\hline 1.8 & AXAIR & PUFF-PLUME & (AX-PF)/AX \\
7.6 & $9.96 \mathrm{E}-03$ & $9.78 \mathrm{E}-03$ & 1.8 \\
10.8 & $3.35 \mathrm{E}-03$ & $3.28 \mathrm{E}-03$ & 2.1 \\
14.1 & $2.56 \mathrm{E}-03$ & $2.51 \mathrm{E}-03$ & 2.0 \\
& $2.25 \mathrm{E}-03$ & $2.20 \mathrm{E}-03$ & 2.0 \\
\hline
\end{tabular}

Table 2. Dose Comparison of AXAIR vs PUFF-PLUME (Stability Class C, Wind speed $4 \mathrm{~m} / \mathrm{s}$ )

\begin{tabular}{|c|c|c|c|}
\hline & \multicolumn{2}{|c|}{ Dose (mrem) } & Percent Diff. \\
Distance $(\mathrm{km})$ & AXAIR & PUFF-PLUME & (AX-PF)/AX \\
\hline 1.4 & $4.10 \mathrm{E}-02$ & $4.07 \mathrm{E}-02$ & 0.7 \\
7.2 & $8.55 \mathrm{E}-03$ & $8.51 \mathrm{E}-03$ & 0.5 \\
9.4 & $6.96 \mathrm{E}-03$ & $6.94 \mathrm{E}-03$ & 0.3 \\
14.4 & $5.45 \mathrm{E}-03$ & $5.43 \mathrm{E}-03$ & 0.4 \\
\hline
\end{tabular}

Table 3. Dose Comparison of AXAIR vs PUFF-PLUME (Stability Class E, Wind speed $8 \mathrm{~m} / \mathrm{s}$ )

\begin{tabular}{|c|c|c|c|}
\hline & \multicolumn{2}{|c|}{ Dose (mrem) } & Percent Diff. \\
Distance (km) & AXAIR & PUFF-PLUME & (AX-PF)/AX \\
\hline 1.4 & $3.11 \mathrm{E}-02$ & $3.19 \mathrm{E}-02$ & -2.6 \\
7.6 & $2.15 \mathrm{E}-02$ & $2.16 \mathrm{E}-02$ & -0.5 \\
10.1 & $1.60 \mathrm{E}-02$ & $1.61 \mathrm{E}-02$ & -0.6 \\
14.4 & $1.30 \mathrm{E}-02$ & $1.30 \mathrm{E}-02$ & 0.0 \\
\hline
\end{tabular}




\subsection{EXPECTED MODEL DIFFERENCES}

As stated previously, the above comparison was done with specific input to ensure that none of the special algorithms (e.g. fumigation) were invoked in AXAIR. There are many situations that exist in which the models will not yield similar answers for various reasons. Each of these reasons are addressed below in detail.

\subsection{Release Height Correction}

PUFF-PLUME does not consider terrain, but AXAIR takes into account the terrain height in determining the effective height of the release using the following equation:

$\mathrm{H}_{\mathrm{e}}=\mathrm{H}_{\mathrm{s}}-\mathrm{H}_{\mathrm{t}}$

where

$\mathrm{H}_{\mathrm{e}} \quad$ the effective release height;

$\mathrm{H}_{\mathrm{s}} \quad$ stack release height as input by the user; and

$\mathrm{H}_{t}$ the terrain height for the given receptor location.

Per NRC 1.145 the terrain height is taken to be the maximum height difference between the receptor and the release location. If the input release height into AXAIR is increased by the terrain height in the sector of interest, the effective release height for the two models will be the same. These adjustments were made for the case that was previously compared, and the two models are in close agreement with this change made.

Depending on which sector is chosen, or which sector the worst $99.5 \%$ dose is determined to be in, the terrain can vary by as much as 40 meters at, $15 \mathrm{~km}$ from the source. This could greatly effect the difference in results being given by the two models. Due to where $\mathrm{H}_{e}$ appears in the formula for determining the relative air concentration, as $\sigma_{z}$ decreases and the terrain height increases the differences will become more significant.

\subsection{Fumigation}

On a clear morning shortly after the sun rises, the earth begins to heat up as the inversion due to the night-time radiating of the earth dissipates. Some time after sunrise the inversion which is present just above the top of the stack acts as a lid to the shallow unstable layer next to the ground. This condition is known as fumigation. Fumigation occurs in stable conditions and vertical spreading is more prominent on the lower side of the plume rather than the upper. AXAIR follows the guidance of NRC 1.145 which states that for inland sites such as the 
Savannah River Site fumigation is allowed to occur for $25 \%$ of the time when all of the following conditions are met:

1) atmospheric conditions are stable (stability categories E, F, or G);

2) wind speed at the release height is less than $4 \mathrm{~m} / \mathrm{s}$;

3) within the distance from the source where the ground level air concentration for fumigation is not higher than those without fumigation for an effective stack height of zero. (Effective inversion height $>\operatorname{SQRT}(\pi / 2) \sigma_{z}$ ). The effective inversion height is the inversion height reduced by the terrain height.

Only when all three of these conditions are met will the fumigation algorithm be invoked. Shown below is the equation used for non-fumigation conditions.

$$
\frac{X}{Q}=\frac{\exp \left(-h_{\mathrm{e}}^{2} / 2 \sigma_{\mathrm{z}}^{2}\right)}{\pi \sigma_{z} \sigma_{y} U_{h}}
$$

Where

$\mathrm{X} / \mathrm{Q}$ - is relative air concentration, sec/m3;

$h_{e} \quad$ is effective stack height (stack height - terrain height), $m$;

$\sigma_{\mathrm{y}} \quad$ lateral plume spread, $\mathrm{m}$;

$\sigma_{\mathrm{z}} \quad$ vertical plume spread, $\mathrm{m} ;$ and

$U_{h} \quad$ wind speed representing conditions at the release height, $\mathrm{m} / \mathrm{sec}$.

The fumigation equation is shown as Equation 2.

$$
\frac{X_{f}}{Q}=\frac{1}{(2 \pi)^{0.5} \sigma_{y} h_{e} U_{h_{e}}}
$$

Where

$U_{h_{e}} \quad$ wind speed representative of the fumigation layer of depth $h_{e}, \mathrm{~m} / \mathrm{s}$

The fumigation $X / Q$ is only used when it exceeds the non-fumigation $X / Q$. Even though PUFF-PLUME does not implicitly include fumigation, the user is expected to choose the appropriate stability class and.wind speed class if the user wishes to analyze these effects. 


\subsection{Interpolation}

As described in section 2.0 AXAIR determines the dose for the 99.5\% meteorology conditions by interpolating between the two classes that bracket the $0.5 \%$ exceedance probability, and these classes are not likely to be adjacent. The interpolation will contribute some error. The stability classes have the following correspondence A-G correspond to 1-7 directly. The wind speed categories are shown in Table 4.

Table 4. Wind Speed Category Ranges

\begin{tabular}{|c|c|}
\hline Category & $\begin{array}{c}\text { Wind Speed } \\
\text { Range }(\mathrm{m} / \mathrm{s})\end{array}$ \\
\hline 1 & $0-2$ \\
2 & $2-4$ \\
3 & $4-6$ \\
4 & $6-8$ \\
5 & $8-12$ \\
6 & $>12$ \\
\hline
\end{tabular}

Shown in Table 5 is a sample of the ranking of dose along with corresponding cumulative frequency, stability class, and wind speed for a particular sector. For the case shown, the interpolation would occur between the two marked cases $\left(^{*}\right)$ which correspond to stability class 6 with wind speed class 2 and stability class 3 with wind speed class 2 . Interpolating between these two doses to determine the $0.5 \%$ cumulative frequency results in a dose of $2.30 \mathrm{E}-04 \mathrm{rem}$. Note that the doses cannot be found by choosing an intermediate class. For example, an incorrect comparison would be to choose an intermediate class for comparison of either stability 4 or 5 with a wind speed class of 2 . Notice that these two combinations of stability and wind speed classes results in doses with a cumulative frequency of less than $0.5 \%$. The dose for each of these is also almost a factor of two higher than the dose determined by interpolation.

Instances such as this have arisen in the past and concern was raised that PUFF-PLUME was determining doses that were higher than the $99.5 \%$ doses that were being reported by AXAIR. The above logic explains why the user can not choose a class between the two. The conservative comparison would be to choose the first one listed for the interpolation (In this example stability class 6 and wind speed class of 2). With this choice made, the comparison should be more favorable with AXAIR being the bounding case with the $99.5 \%$ reported dose. 


\subsection{Source Size}

AXAIR assumes that the initial source size is infinitesimally small whereas in PUFF-PLUME the user is allowed to enter the initial plume size. In PUFFPLUME this initial plume size value is used in the following manner. The initial dimensions of the plume are input as $\sigma_{\mathrm{oy}}$ by $\sigma_{\mathrm{oz}}$, in meters. The value of $\sigma_{\mathrm{y}}$ to be used in the determination of the relative air concentrations is $\operatorname{SQRT}\left(\sigma_{\mathrm{y}}{ }^{2} \mathrm{~B}+\sigma_{\mathrm{oy}}^{2}\right)$

Table 5. Sample Ranking of Dose

\begin{tabular}{|c|c|c|c|}
\hline $\begin{array}{c}\text { Dose } \\
\text { (rem) }\end{array}$ & $\begin{array}{c}\text { Cumulative } \\
\text { Frequency (\%) }\end{array}$ & $\begin{array}{c}\text { Stability } \\
\text { Class }\end{array}$ & $\begin{array}{c}\text { Wind } \\
\text { Speed }\end{array}$ \\
\hline $7.97 \mathrm{E}-04$ & 0.018 & 4 & 1 \\
$7.79 \mathrm{E}-04$ & 0.030 & 5 & 1 \\
$4.43 \mathrm{E}-04$ & 0.091 & 5 & 2 \\
$4.05 \mathrm{E}-04$ & 0.194 & 4 & 2 \\
$4.01 \mathrm{E}-04$ & 0.226 & 3 & 1 \\
$2.68 \mathrm{E}-04$ & 0.297 & 5 & 6 \\
$2.65 \mathrm{E}-04$ & 0.420 & 4 & 6 \\
$2.32 \mathrm{E}-04$ & 0.438 & 6 & 2 \\
$2.27 \mathrm{E}-04$ & 0.612 & 3 & 2 \\
$2.16 \mathrm{E}-04$ & 0.687 & 2 & 1 \\
$1.98 \mathrm{E}-04$ & 0.698 & 4 & 4 \\
$1.79 \mathrm{E}-04$ & 1.072 & 1 & 1 \\
$1.46 \mathrm{E}-04$ & 1.075 & 7 & 2 \\
\hline
\end{tabular}

where $\sigma_{\mathrm{yPB}}$ is the value determined using the Pasquill-Briggs equations. The value for $\sigma_{z}$ is determined in the same manner. The default values of initial plume size in PUFF-PLUME are $3 \mathrm{~m}$ by $3 \mathrm{~m}$. For relatively unstable categories with large values of $\sigma_{\mathrm{y}}$ and $\sigma_{\mathrm{z}}$ the initial plume size becomes negligible. In the classes that are more stable where $\sigma_{z}$ can be as low as 10 or $20 \mathrm{~m}$, the initial plume size can greatly effect the results.

\subsection{Inversion Height}

In AXAIR the inversion or lid height is set to a constant value of 200 meters whereas in PUFF-PLUME the user has the option of entering the inversion height of their choice. The value of $\sigma_{\mathrm{z}}$ is allowed to be no greater than $0.8 * \mathrm{H}_{\mathrm{inv}}$ so even though $\mathrm{H}_{\text {inv }}$ is not directly in the $\mathrm{X} / \mathrm{Q}$ equation, it can have an impact on the resulting doses that are determined using PUFF-PLUME. This would have the greatest effect for the unstable classes (A, and B) and possibly at greater 
distances $(\mathrm{d}>3 \mathrm{~km}$ ) for the intermediate classes (C and D). This should not effect stability classes $\mathrm{E}$ and $\mathrm{F}$.

\subsection{Inhalation and Shine Doses}

PUFF-PLUME considers only inhalation dose while AXAIR considers both inhalation and shine dose. Depending on the isotope considered this can have an effect on the comparison being made between the two models. Isotopes that highly contribute a shine dose will result in a higher dose being determined by AXAIR

\subsection{Meander}

Meander occurs when the plume at any instant fluctuates about some mean position. Although the meander subroutine is only invoked in AXAIR under certain conditions resulting from a vent release, several questions have arisen concerning the effect on the output doses. The meander algorithms are never invoked when a stack release is considered.

\subsection{Breathing Rates}

The adult breathing rate previously and currently used in both of the models to determine the maximum individual offsite dose is $12,000 \mathrm{~m}^{3} / \mathrm{yr}$.

\subsection{CONCLUSIONS}

The above discussions support that the methodologies in AXAIR and PUFFPLUME are similar when the dispersion coefficients are the same. However as discussed above, there are specific cases when the two models should not be compared directly. These differences are due to the different functions of the two models and the invocation of special algorithms in AXAIR. 


\subsection{REFERENCES}

1. F. Pasquill. "Atmospheric Dispersion Parameters in Gaussian Plume Modeling." Part.II. EPA-600/4-76-030b U.S. Environmental Protection Agency, Office of Research and Development, Environmental Sciences Research Laboratory, Research Triangle Park, NC 27711 (1976).

2. J. L. Monteith, Ed.. Vegetation and the Atmosphere. Academic Press, New York (1975).

3. Pasquill, F., The Estimation of the Dispersion of Windborne Material, Meteorol. Mag., 90(1093):33-49, 1961.

4. Pasquill, F., Atmospheric Diffusion, D. Van Nostranc Company, Ltd., London 1962.

5. Atmospheric Dispersion Models for Potential Accidental Consequence Assessments at Nuclear Power Plants, US NRC Regulatory Guide 1.145, US Nuclear Regulatory Commission, Washington, DC, Rev. 1, November 1982.

6. Garrett, A. J. and C. E. Murphy, Jr., A Puff-Plume Atmospheric Deposition Model for Use at SRP in Emergency Response Situations, DP1595, E. I. du Pont de Nemours \& Co., Savannah River Laboratory, Aiken, SC, 1981.

7. Weber, A. H., Dispersion Coefficients Used in Puff-Plume and AXAIR, SRT-ETS-930273, Westinghouse Savannah River Company Inter-Office Memorandum, Savannah River Technology Center, Aiken, SC, 1993. 


\section{APPENDIX A. Code Input Used for Comparison}

The following parameters were input into the models for the comparison. Note the meteorological data base and dispersion coefficients were also changed in AXAIR so this run will be unable to be duplicated without these features. If there is a blank in either column it is due to the fact that the model does not require that item as an input. If the item is followed by an asterisk $(*)$, it is hard modeled into the code.

Table A1. Input Parameters for AXAIR and.PUFF-PLUME Comparison

\begin{tabular}{|l|l|l|}
\hline Parameter & AXAIR & PUFF-PLUME \\
\hline Release Area & A & A \\
Stack Height & $61 \mathrm{~m}$ & $61 \mathrm{~m}$ \\
Sector & S & - \\
Dose Factor Library & ICRP 30 & ICRP $30^{*}$ \\
Isotope & I-131 & I-131 \\
Amount of Release (Ci) & 1.00 & 1.00 entered as \\
Duration of Release & 120 & $1.390 \mathrm{E}-04 \mathrm{Ci} / \mathrm{sec}$ \\
(min) & & 120 \\
Inversion Height (m) & $200^{*}$ & 200 \\
Sigmaz (Class A) & $25^{*}$ & 25 \\
(Class C) & $15^{*}$ & 15 \\
(Class E) & $5^{*}$ & 5 \\
\hline
\end{tabular}




\section{APPENDIX B. Comparison using Unmodified Code Versions.}

AXAIR and PUFF-PLUME were compared as the casual user would be able to compare them without modifications to the existing coding. For this comparison we used the parameters for a case that had been used in the past. The input parameters are listed below in Table B1.

Table B1. Input Parameters for AXAIR and PUFF-PLUME Comparison

\begin{tabular}{|l|l|l|}
\hline Parameter & AXAIR & PUFF-PLUME \\
\hline Release Area & $\mathrm{H}$ & $\mathrm{H}$ \\
Vent Height & $0 \mathrm{~m}$ & $0 \mathrm{~m}$ \\
Dose Factor Library & ICRR 30 & ICRP 30* \\
Isotope & Pu-238 & Pu-238 \\
Amount of Release (Ci) & 1.00 & 1.00 entered as \\
& & $1.390 \mathrm{E}-04 \mathrm{Ci} / \mathrm{sec}$ \\
Duration of Release & 120 & 120 \\
(min) & & 200 \\
Inversion Height (m) & $200^{*}$ & \\
\hline
\end{tabular}

First, the AXAIR code was executed in order to determine the stability and wind speed classes that were to be used for the PUFF-PLUME comparison. As stated earlier, as part of the output AXAIR shows the two sets of stability and wind speed combinations that were interpolated between in order to find the $99.5 \%$ dose. The dose at the site boundary was determined by interpolating between $F$ stability with $6-8 \mathrm{~m} / \mathrm{s}$ wind speed and E stability with $2-4 \mathrm{~m} / \mathrm{s}$. wind speed which correspond to AXAIR denotation as 6-4 and 5-2, respectively. These correspond to doses that were not exceeded $99.6 \%$ and $98.92 \%$ of the time, respectively. This bracketing combination was used for the PUFF-PLUME comparison. These resulting doses are depicted in Table B2 for the site boundary.

Table B2. PF-PL and AXAIR Comparison at the Site Boundary

\begin{tabular}{|c|c|c|c|}
\hline Met Data & \multicolumn{3}{|c|}{ EDE (rem) } \\
\hline & AXAIR & PF-PL & $\%$ Difference \\
\hline F $7 \mathrm{~m} / \mathrm{s}$ & 1.01 & 1.08 & $8 \%$ \\
\hline E $3 \mathrm{~m} / \mathrm{s}$ & 0.627 & 0.670 & $7 \%$ \\
\hline
\end{tabular}

This comparison is addressed in greater detail in Inter-Office Memorandum SSE-ETS-93-0234 ${ }^{\mathrm{B} 1}$. Referring to Table B1, some differences could still be seen 
due to the wind speeds used in each of the codes. For example, AXAIR applies a historical average wind speed within the given range whereas for the comparison the midpoint of the range was chosen for input into PUFF-PLUME. This shows that the results of the comparison of AXAIR and PUFF-PLUME are indeed in agreement.

B1. Hädlock, D. J., AXAIR and PUFF-PLUME Comparison(U), SSE-ETS-930234, Westinghouse Savannah River Company Inter-Office Memorandum, Savannah River Site, Aiken, SC, 1993. 
AXAIR And PUFF-PLUME Comparison

\section{DISTRIBUTION (30)}

R. P. Addis, 773A

K. S. Beard, 706-9C

A. L. Boni, 773A

W. H. Carlton, 773A

M. L. Cowen, $992 \mathrm{~W}-1$

J. M. East, 992W-1

D. Hadlock, 706-9C

D. M. Hamby, 773A

C. H. Hunter, 773A

R., J. Kurzeja, 773A

J. W. Lightner, 706-9C

K. R. O'Kula, 992W-1

L. M. Papouchado, 773A

M. S. Rabin, 992W-1

A. A. Simpkins, 773A

A. H. Weber, 773A

SRTC Records(4), 773-52A

EDG Records(10), 773A 